in the community, third-sector and statutory organisations, can all contribute.

For general practice and primary care this will certainly require different training and more resources. The experience for all could be quite different: an individual with 'stress' booking straight into their choice of groups run by Improving Access to Psychological Therapies (IAPT) services; a patient with psychosis booking their follow up with the practice-based community psychiatric nurse through GP receptionists; a third-sector practitioner liaising with a GP to discuss the mutually accessible online shared plan for an individual with psychosis; a GP calling a psychiatrist to discuss reducing doses of antipsychotic medication for a patient the psychiatrist had seen as a one off at the practice; the practice-based IAPT practitioner providing cognitive behavioural therapy for anxiety as part of the aftercare plan following community-based alcohol detoxification. All possible with a small shift in allocation of NHS resources.

\section{Richard Byng,}

Professor in Primary Care Research and GP with a Special Interest in Mental Health, Plymouth University, Plymouth. E-mail: richard.bynglaplymouth.ac.uk

\section{REFERENCES}

1. Green B, Gowans WJ. Mental health care in hospitals and primary care: an unsustainable balance. Br J Gen Pract 2015; DOI: 10.3399/ bjgp15X683365

2. The Mental Health Policy Group. A manifesto for mental health. 2015. http://wnw.mentalhealth.org. uk/content/assets/PDF/publications/manifestobetter-mental-health.pdf (accsessed 4 Mar 2015).

3. Knapp M, Andrew A, McDaid D, et al. Investing in recovery: making the business case for effective interventions for people with schizophrenia and psychosis. Rethink Mental Illness. 2014. http://wnw. rethink.org/media/1030280/investing_in_recovery. pdf (accsessed 4 Mar 2015).

4. Murphy S, Irving CB, Adams CE, Driver R. Crisis intervention for people with severe mental illnesses. Cochrane Database Syst Rev 2012; 5: CD001087.

5. Stanton E, Baggaley M. Are mental health patients getting the right treatment? Results from a comprehensive review of patient notes. 2012. http:// beaconhs.co.uk/wp-content/uploads/2015/02/ beacon-uk-assessing-mental-healthcare.pdf (accsessed 4 Mar 2015).

DOI: 10.3399/bjgp15X684325

\section{Digital mental health services in general practice}

Claire Harding and colleagues have highlighted the potential of digital interventions in general practice and the need for NHS accredited or 'kitemarked' apps, but also raise questions about the need for evidence of their safety and efficacy. ${ }^{1}$

They state that '... there is broad consensus in the field that traditional randomised controlled trials are not fit for purpose with digital interventions llargely because services develop and expectations change faster than trials can be run) .... We acknowledge that good interventions take time to develop and test, but do not agree that this is a reason to abandon evidencebased practice. Users and commissioners should expect robust evidence before choosing to invest time or resources in such interventions.

For simple health information on the web, common sense 'kitemarking' may be sufficient. However, for interventions aimed at behaviour change, randomised controlled trials are warranted, regardless of whether they are delivered digitally. Rapid changes in services are not sufficient reason to negate this necessity, as welldeveloped interventions can be adapted to new delivery systems.

Miriam Santer,

Clinical Lecturer, University of Southampton, Southampton. E-mail: m.santerlasoton.ac.uk
Hazel Everitt,

Clinical Lecturer, University of Southampton, Southampton.

\section{REFERENCE}

1. Harding $C$, Ilves $P$, Wilson S. Digital mental health services in general practices. Br J Gen Pract 2015 DOI: 10.3399/bjgp15X683377.

DOI: 10.3399/bjgp15X684337

\section{Endometriosis in secondary care}

As a hospital gynaecologist I may not be the best person to comment on your article but these are my thoughts. Symptoms that could be due to endometriosis are extremely common in both primary care and the hospital gynaecology clinic. With the exception of women who are currently trying to conceive, it is perfectly reasonable to treat these symptoms hormonally. The earlier Royal College of Obstetricians and Gynaecologists guideline as well as the more recent European guideline you quote, both recommend treating symptoms with either the combined contraceptive pill, an ovulation suppressing progesterone-only pill, or the Mirena ${ }^{\circledR}$ interauterine system. Women referred to hospital because of the supposed importance of early diagnosis may be disappointed to be offered precisely those treatments if they attend a consultant clinic.

Stewart Pringle,

Consultant Gynaecologist, South Glasgow University Hospitals, Glasgow.

E-mail: stewartpringleanetscape.net

\section{REFERENCE}

1. Johnston JL, Reid H, Hunter D. Diagnosing endometriosis in primary care: clinical update. $\mathrm{Br}$ J Gen Pract 2015; DOI: 10.3399/bjgp15X683665.

DOI: 10.3399/bjgp15X684349 